\title{
Síndrome de Gorlin-Goltz
}

\section{Reporte de un caso}

Rubio-Alfaro L

\section{Introducción}

El síndrome de Gorlin-Goltz en un desorden autosómico dominante, caracterizado por una predisposición cancerígena y múltiples defectos de la piel, sistema nervioso, ojos, glándulas endocrinas y huesos con expresión variable. Fue reportado por primera vez en 1894 por Jarish y White, y descrito posteriormente entre 1950 y 1960 por Gorlin y Goltz. Los pacientes tienen propensión a desarrollar carcinomas basocelulares de la piel, múltiples queratoquistes en los maxilares, meduloblastomas y fibromas ováricos. También se le conoce como síndrome de cacinoma nevo basocelular, Síndrome de carcinoma nevoide de células basales, polioncosis - cutáneo - mandibular hereditaria o quinta facomatosis. Se presenta el reporte de un caso clínico atendido en la ciudad de San Luis Potosí en el Hospital Central Dr. Ignacio Morones Prieto. LUXMÉDICA 2010;5(14): 33-39

\section{Presentación del caso}

Ficha de identificación: Femenino de 9 años de edad, con escolaridad de tercero de primaria, originaria de la ciudad de San Luis Potosí y residente de la misma, de religión católica.

Antecedentes Heredo Familiares: Abuela materna y paterna con HTA, abuelo materno con diabetes mellitus tipo 2 (DM2), tios abuelos maternos con DM2, hermana con fisura labio-palatina.

Antecedentes Personales No Patológicos: Habita casa con todos los servicios, 3 recámaras, 6 habitantes, zoonosis con peces, hábitos de higiene adecuados (aseo personal diario incluyendo cambio de prendas íntimas, aseo dental 2 veces por día), hábitos alimenticios adecuados en cantidad y calidad, inmunizaciones completas hasta la fecha.

Estudiante del décimo semestre de Medicina, UAA. 
Antecedentes Perinatales: Producto de primigesta, embarazo normoevolutivo, resolución por cesárea debido a sospecha de producto macrosómico, producto pretérmino (8 meses), peso de $3900 \mathrm{gr}$, talla de $49 \mathrm{~cm}$, presento cianosis a los 15 minutos de nacimiento, permaneció en incubadora por 1 día y en fototerapia por 2 días. Alimentación por seno materno hasta los 8 meses, inicio ablactación a los 7 meses y destete al año. Desarrollo psicomotriz con sostén cefálico a los 4 meses, inicio demabulación a los 12 meses, fonemas a los 2 años.

Antecedentes Personales Patológicos: A los 2 años de edad presentó varicela sin secuelas posteriores, también presentó crisis convulsivas febriles y posteriormente también a la edad de 4 años. A los 6 años sufrió traumatismo cortante en mano izquierda que le ocasionó sección de tendones flexores, por lo que se realizó corrección quirúrgica.

Padecimiento actual: Inicia en septiembre de 2008 con dolor moderado en zona de maxilar superior derecho por lo que fue llevada al IMSS donde le proporcionan tratamiento con aspirina y paracetamol presentando leve mejoría. También refiere disminución de la agudeza visual en ojo izquierdo

Es referida con médico genetista.

Continúa el aumento de volumen de la zona, hasta mostrar asimetría facial evidente, por lo que es referida a consulta de cirugía maxilofacial.

\section{Exploración Física:}

- Peso: $42.4 \mathrm{~kg}$ (pc 95)

- TA: $110 / 70 \mathrm{mmHg}$

- FC: $80 x^{\prime}$

- FR: $24 x^{\prime}$

- Temperatura: $37^{\circ} \mathrm{C}$

- Edad aparente mayor a la cronológica

- Frente prominente

- Hipertelorismo ocular

- Puente nasal pequeño y aplanado

- Prognatismo

- Cuello corto

- Espacio interdental aumentado

- Múltiples procesos carios incipientes

- Higiene regular
- Aumento de volumen en fondo de saco vestibular maxilar derecho desde OD 55 (primer molar superior) hasta tuberosidad del maxilar, indurado a la palpación bien circunscrito, no doloroso, sin datos de secreción

- No hay visceromegalias

- Genitales en Tanner 1

- Extremidades superiores alargadas

- Extremidades inferiores con genu valgo

- Piel y tegumentos normocrómicos e hidratados.

- Resto sin datos de relevancia.

Exámenes de laboratorio y gabinete:

14sept09: Hb $13.8 \mathrm{~g} / \mathrm{dL}$, Hto $42.5 \%$, plaquetas $286000 \mathrm{cel} / \mathrm{mm}^{3}$, TP 13.2 "TTP 31.6" 

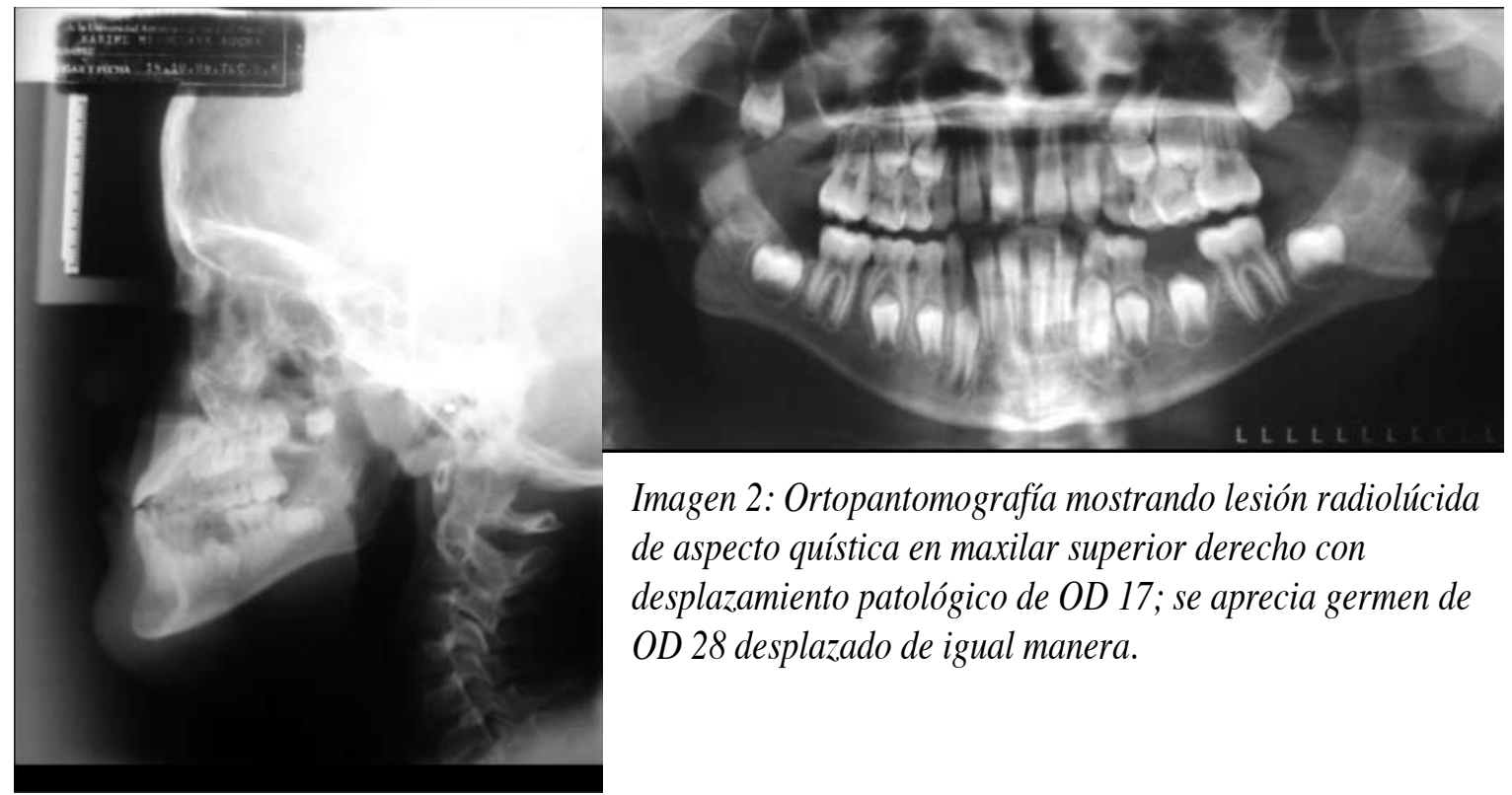

Imagen 2: Ortopantomografía mostrando lesión radiolúcida de aspecto quística en maxilar superior derecho con desplazamiento patológico de OD 17; se aprecia germen de OD 28 desplazado de igual manera.

Imagen 1: Radiografia cefálica lateral donde se aprecia quiste en maxilar superior derecho.

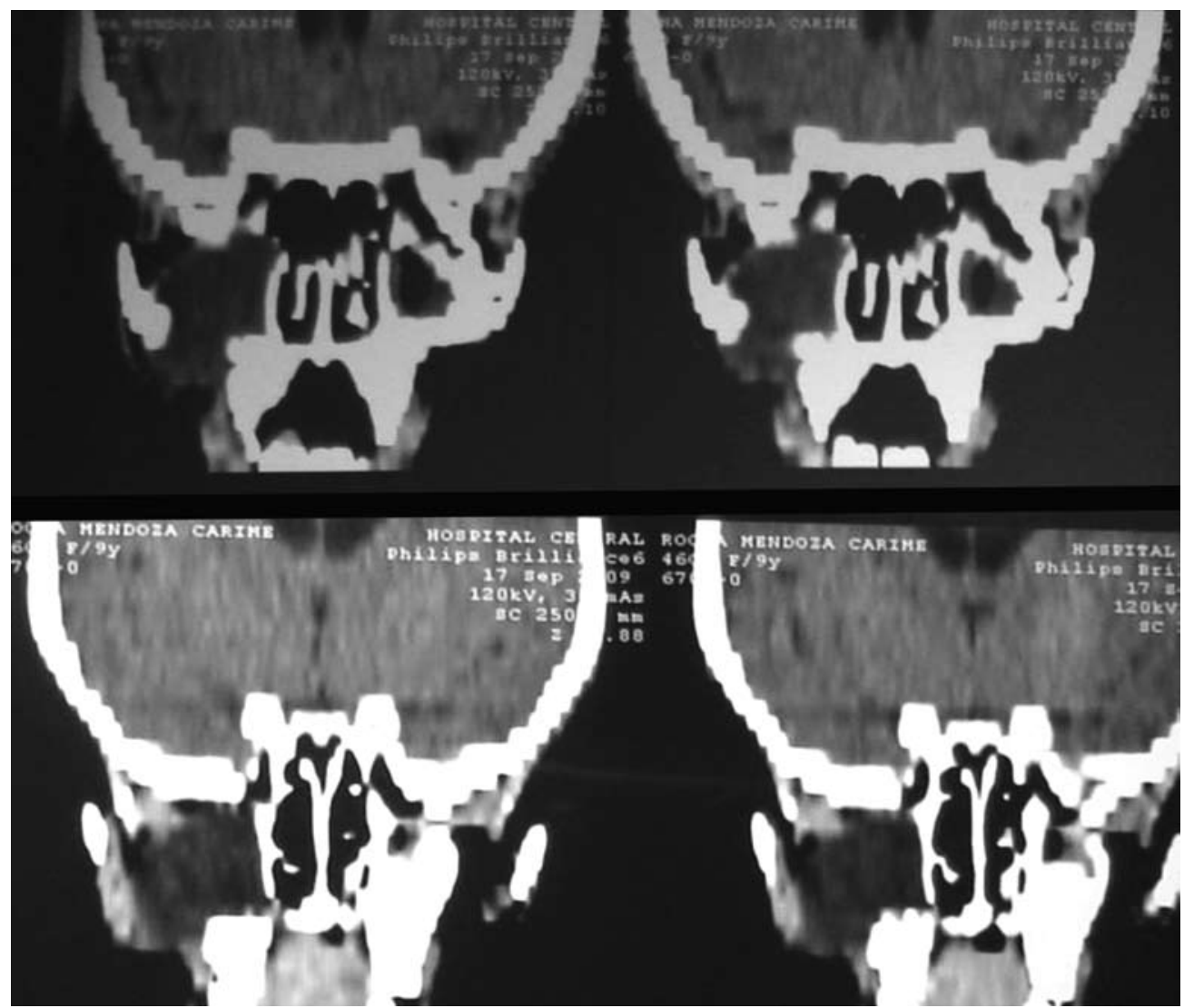

Imagen 3 y 4: TAC de macizo facial donde se pueden apreciar los límites anatómicos de la lesión. 

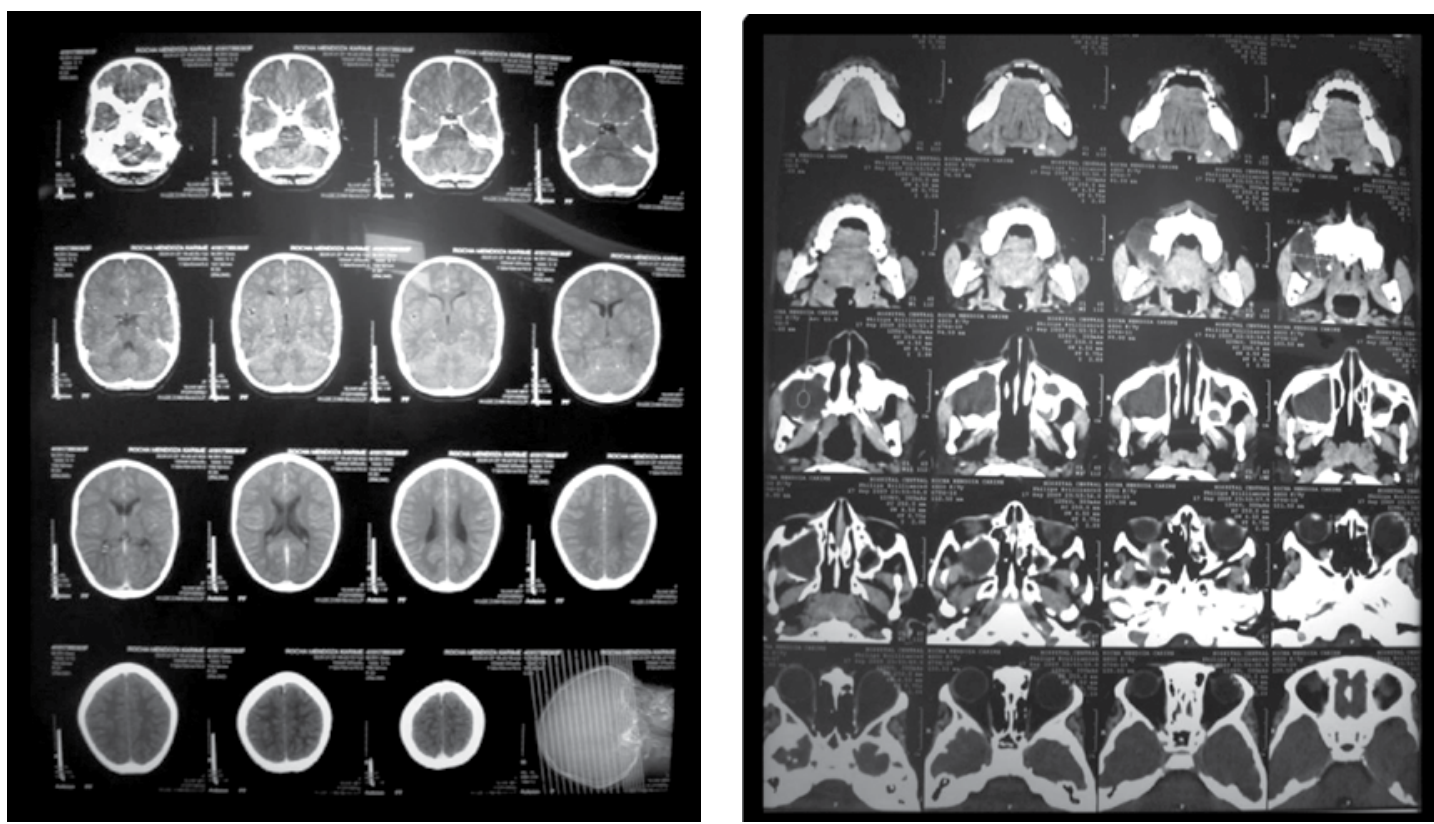

Imagen 5: TAC simple de cráneo, de apariencia normal

Imagen 8: RM de cara en donde se aprecia tamaño de la lesión.

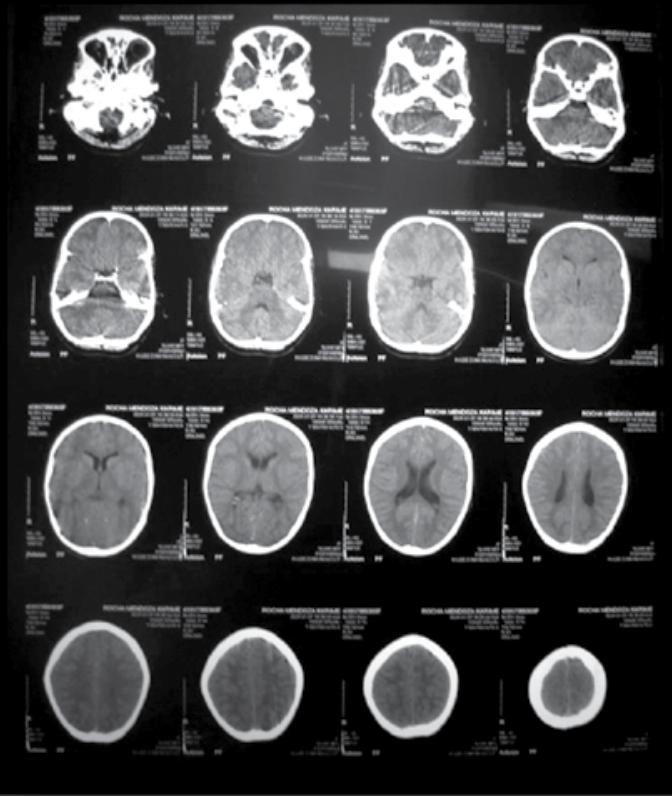

Imagen 6: TAC contrastada de cráneo de apariencia normal

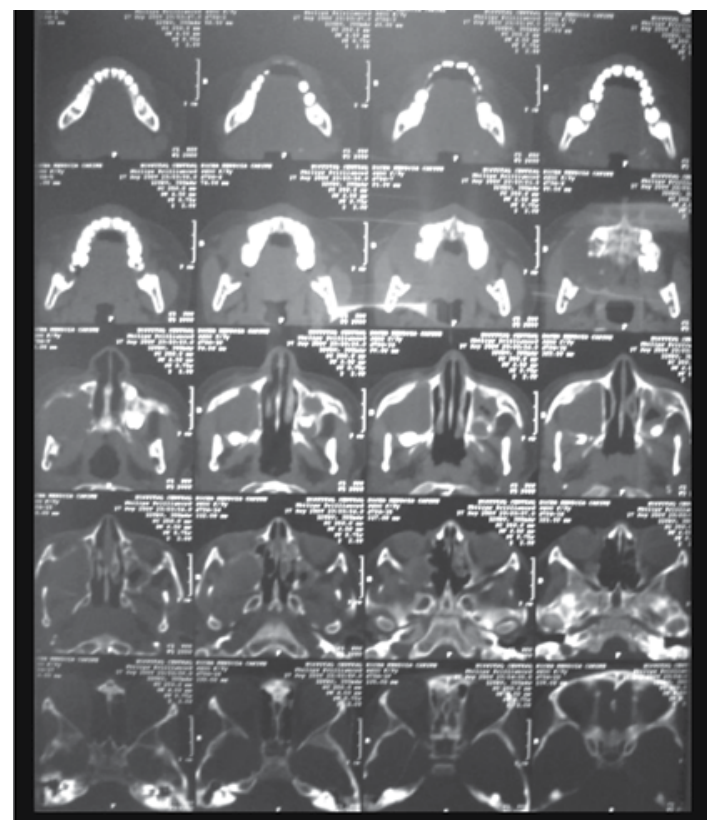

Imagen 9: $R M$ de cara en $T 2$ 


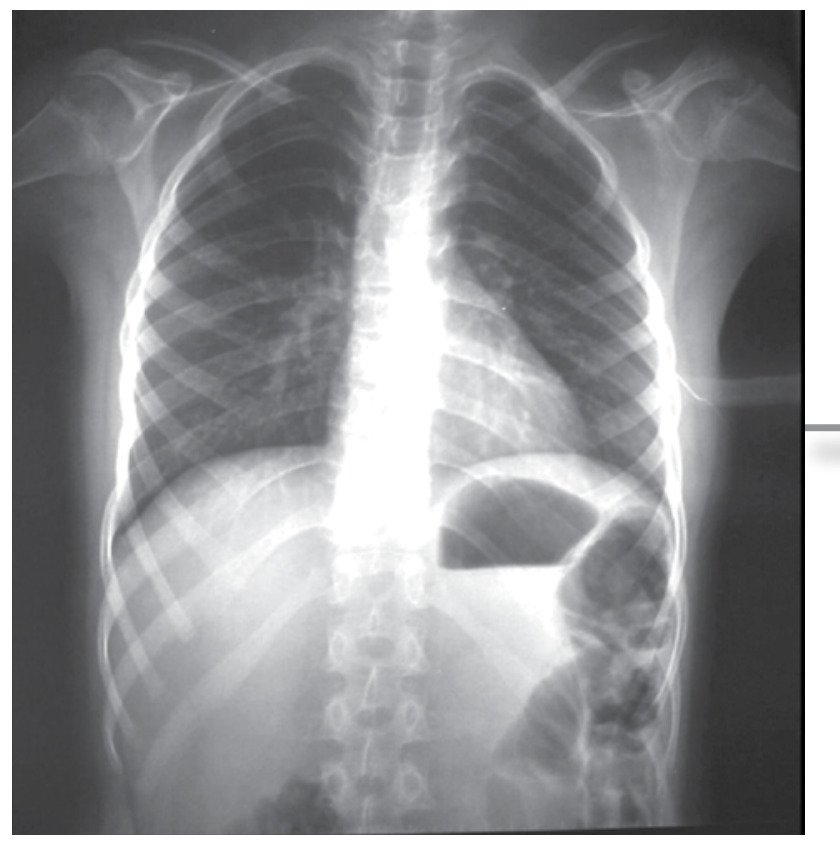

Imagen 10: radiografía de tórax mostrando costilla bifida.

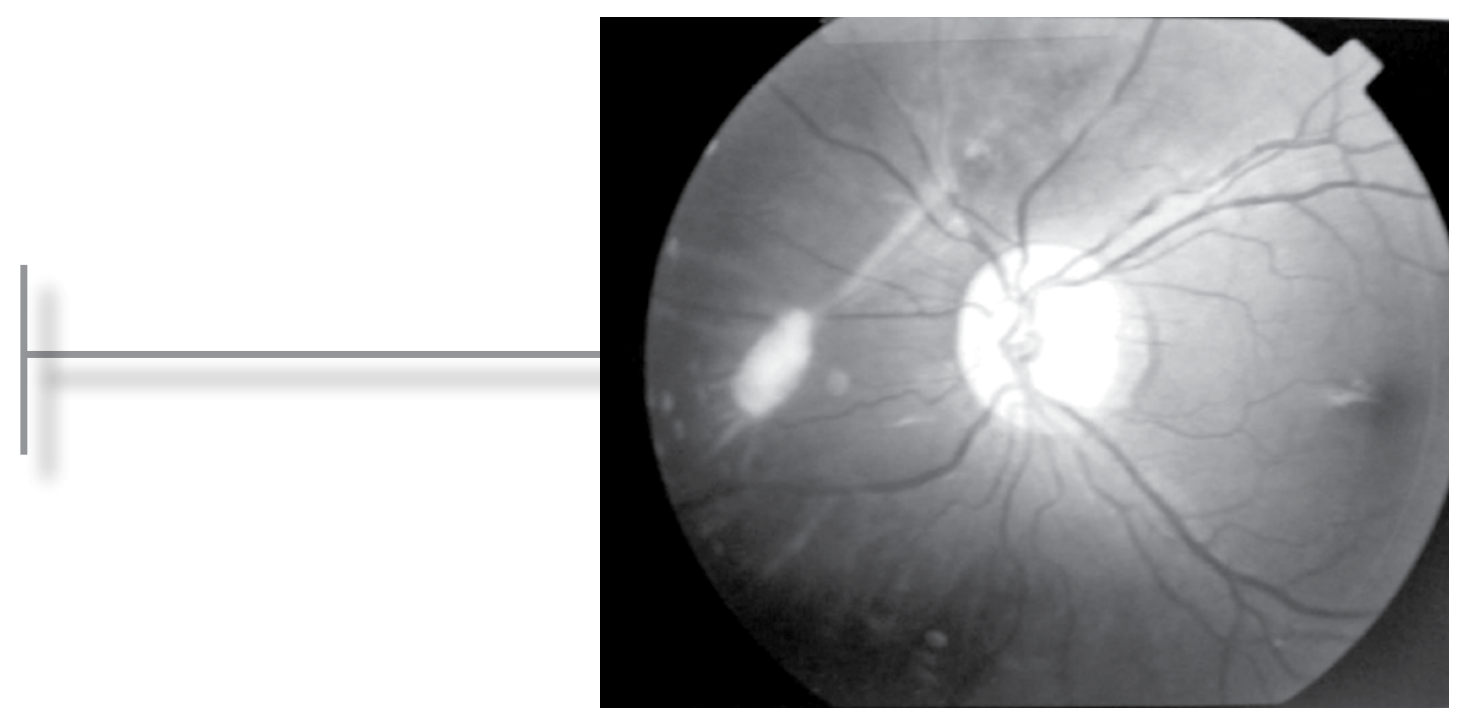

Imagen 11: imagen de la retina mostrando fibrosidad blanda en ojo derecho.

Biopsia por aspiración: se obtienen 20 cc de material blanco amarillento viscoso. Se obtiene muestra de epitelio de la capsula de la lesión.

Reporte de biopsia: queratoquiste odontógeno, proceso xantogranulomatoso.
Reporte postquirúrgico: se encuentra cavidad quística en región maxilar superior, la cual se extiende hacia su borde superior y posterior con contenido caseoso y epitelio adherido a la mucosa oral en su cara externa, con presencia de gérme- 
nes dentales de OD 18, asi como cavidad quística de similares características en maxilar superior izquierdo, con menor extensión y con involucro de gérmenes dentarios de OD 27 y 28.

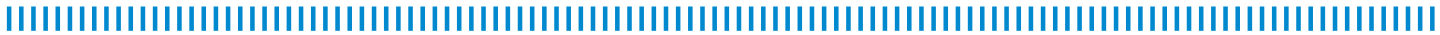

\section{Discusión}

El síndrome de Gorlin-Goltz es un desorden clínico poco frecuente hereditario de carácter autosómico dominante con penetrancia levada (97\%) y expresión fenotípica variable. Se caracteriza por múltiples nódulos cutáneos en piel no expuesta al sol y también en piel de cara que tienden a malignizarse como nevos de células basales, queratoquistes odontógenos múltiples, hipertelorismo, amplia raíz nasal. En la mayoría de los casos se manifiesta a temprana edad o cerca de la pubertad con edad de diagnóstico promedio que varía desde los 5 hasta los 30 años de edad, afecta más a la raza blanca y por igual a ambos sexos.

Nomland en 1932 fue el primero que dio individualidad a este proceso de "epiteliomas basales múltiples", pero no observó otras características muy frecuentes, fue hasta 1939 cuando Straith las asoció con los quistes maxilares. Em 1951, Binkley y Johnson comprobaron que el cuadro descrito por Nomland aparecía asociado a muchas malformaciones cutáneas y extracutáneas, pero hasta 1960 Gorlin y Goltz realizaron un estudio genético de gran valor para esta entidad.

La Clasificación Internacional de Enfermedades Aplicadas a la Odontología y Estomatología (CIE - AO) lo incluye dentro de las anomalías congénitas y otras hamartomatosis.

Se ha demostrado en diferentes investigaciones la asociación de este síndrome con mutaciones en el gen PATCHED localizado en el cromosoma 9q22.3-q31 y 1p32. La biología molecular de los tumores que aparecen en este síndrome es similar a la del retinoblastoma caracterizada por una mutación en un oncogen recesivo. El gen PTCH actua tanto en el desarrollo del in- dividuo como en la supresión tumoral. Las anomalías congénitas son consecuencia de la mutación en una de las copias de este gen mientras que la aparición de tumoraciones requiere la mutación de las dos copias. La incidencia del síndrome de ese 1 por cada 50,000-150,000 habitantes.

La lesión cutánea fundamental es el epitelioma basocelular con aspecto nevoide, son elementos papuloides, a veces manchas pigmentadas de milímetros a medio centímetro de diámetro de color oscuro, que se localizan principalmente en la mitad superior de la cara, la segunda localización en frecuencia es el cuello y el tercer lugar es la zona axilar. Otra lesión es el epitelioma de aspecto clásico o común, algunos destructivos del globo ocular. Malformaciones cutáneas como quistes epidermoides-queratoquistes palmo plantares, cicatrices puntiformes o depresiones en manos y pies.

Las lesiones extracutáneas son diversas. En tejido óseo se observan quistes de maxilares (queratoquistes), anomalías costales (sinostosis, costillas ensanchadas, costilla bífida), anomalías vertebrales (escoliosis, cifosis, fusión de vértebras), amplia raíz nasal y otras anomalías óseas (prognatismo, huesos supernumerarios, anomalía de Sprengel). Puede haber también malposición dentaria, retenciones dentarias múltiples y oligodoncia de los incisivos laterales. Son frecuentes la agenesia parcial del cuerpo calloso (meduloblastoma, gliomatosis) y la hidrocefalia. Frecuentemente de observa hipertelorismo. Se puede asociar a fibroma de ovario entre otras anomalías. Kimonis y col. describieron que el diagnóstico para el síndrome debía basarse en la presencia de dos criterios principales o uno principal y dos menores. 


\section{Criterios principales}

- Más de dos carcinomas basocelulares o uno en menor de 20 años.

- Queratoquistes de los maxilares demostrados en estudios histopatológicos.

- Tres o más pits palmares y plantares.

- Calcificación bilaminar de la hoz del cerebro.

- Costillas bífidas fusionadas o marcadamente expandidas.

- Pariente de primer grado con el síndrome.

\section{Criterios menores}

- Macrocefalia determinada después de ajustar edad

- Malformaciones congénitas: fisura labial o palatina, prominencia frontal, fascies anchas, hipertelorismo moderado o severo.

- Otras alteraciones esqueléticas: Deformación de Sprengel, marcada deformación pectoral, marcada sindactilia de los dígitos.

- Anomalías radiográficas: Puente en silla turca, anomalías vertebrales tales como hemivértebras, fusión o elongación de los cuerpos vertebrales, defectos de modelaje de manos y pies, o radiolucidez en forma de llamas en las manos o pies.

- Fibroma de ovario.

- Meduloblastoma.

\section{Bibliografía}

1 Yuli M, Gonzáles JM. Sindrome de Nevus de Células Basales (Gorlin y Goltz). Acta Odontológica Venezolana, 2004; Volumen 42.

2 Pereira DC, Urbizo VJ, Mori EAD, Sindrome de Gorlin. Rev Haban Cienc Med La Habana, 2008; Volumen 7.

3 Miquilarena SME, Meneses VS. Sindrome de Goltz. SVDCD, 1991; 2:39-41.

4 Agurto PJ, Mardones MM, Núñez BC. Síndrome de gorlin-goltz. Rev Otorrinolaringol Cir Cabeza Cuello, 2004; 64: 230-236.

5 Díaz FJM, et al. Síndrome Névico basocelular. Med Oral Patol Oral Cir Bucal, 2005; 10:E57-E66.

6 De-Domingo B, Gonzales F, Lorenzo P. Síndrome de
Los queratoquistes aparecen en la primera década de la vida, son múltiples o multifocales, generalmente en zona de molares. La costilla bífida se reporta en el $50 \%$ de los casos. La calcificación de la hoz del cerebro se encuentra en el $85 \%$ que se observa en radiografías posteroanterior y variantes. También puede observarse hiperneumatización de los senos. Los queratoquistes maxilares representan de $10-12 \%$ de todos los quistes maxilares y 4-5\% de estos se asocian al síndrome nevo basocelular. Los queratoquistes aparecen en un $75 \%$ de los pacientes afectados y suelen ser los primeros síntomas en edades tempranas, por lo general son múltiples afectando maxilares y asintomáticos, pueden desecadenar infecciones y alteraciones en la erupción dental. Las costillas comunmente afectadas como bífidas son la tercera, cuarta y quinta, pero también se ha observado en la primera, segunda, séptima y octava costillas. En el presente caso, se tienen los criterios mayores de quistes odontogénicos y costilla bífida y como criterio menor prominencia frontal e hipertelorismo ocular. No hay presencia de nevos en piel hasta la fecha ni calcificaciones de la hoz del cerebro ni fibromas de ovario.

Esta paciente debe tener seguimiento por el riesgo a desarrollar a edades tempranas algunas de las anormalidades descritas anteriormente.
Gorlin. Arch Soc Esp Oftalmol, 2008; 83: 321-324.

7 Manfredi $M$, et al. Nevoid basal cell carcinoma syndrome: a review of the literature. Int J Oral Maxillofac Surg, 2004: 33: 117-124.

8 High A, Zedan W. Basal Cell Nevus Syndrome. Curr Opin Oncol 2005; 17: 160-166.

9 Mehra P, Murad H. Maxillary Sinus Disease of Odontogenic Origin. Otolaryngol Clin N Am 2004; 37: 347-364.

10 Ozturk A, et al. Neuroradiological findings in a mother and daughter with gorlin syndrome. Clin Dysmorphol 2003; 12: 145-146.

11 Kimonis VE, et al. Radiological features in 82 patients with nevoid basal cell carcinoma (NBCC or Gorlin) syndrome. Genetics in Medicine 2004; 6:495-502. 